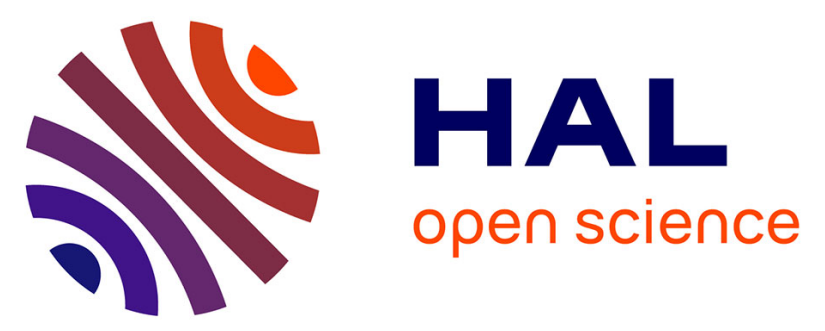

\title{
Incidence of solid organ cancers after liver transplantation: comparison with regional cancer incidence rates and risk factors
}

Christophe Carenco, Stéphanie Faure, Astrid Herrero, Eric Assenat, Yohan Duny, Guillaume Danan, Michael Bismuth, Gerald Chanques, Jose

Ursic-Bedoya, Samir Jaber, et al.

\section{To cite this version:}

Christophe Carenco, Stéphanie Faure, Astrid Herrero, Eric Assenat, Yohan Duny, et al.. Incidence of solid organ cancers after liver transplantation: comparison with regional cancer incidence rates and risk factors. Liver International, 2015, 35 (6), pp.1748-1755. 10.1111/liv.12758 . hal-01767876

\section{HAL Id: hal-01767876 \\ https://hal.umontpellier.fr/hal-01767876}

Submitted on 10 Sep 2018

HAL is a multi-disciplinary open access archive for the deposit and dissemination of scientific research documents, whether they are published or not. The documents may come from teaching and research institutions in France or abroad, or from public or private research centers.
L'archive ouverte pluridisciplinaire HAL, est destinée au dépôt et à la diffusion de documents scientifiques de niveau recherche, publiés ou non, émanant des établissements d'enseignement et de recherche français ou étrangers, des laboratoires publics ou privés. 


\title{
Incidence of solid organ cancers after liver transplantation: comparison with regional cancer incidence rates and risk factors
}

\author{
Christophe Carenco, Stéphanie Faure, Astrid Herrero, Eric Assenat, Yohan Duny, Guillaume Danan, \\ Michaël Bismuth, Gérald Chanques, José Ursic-Bedoya, Samir Jaber, Dominique Larrey, Francis Navarro and \\ Georges-Philippe Pageaux
}

Digestive department, Liver Transplantation Unit - Saint-Eloi Hospital, Monterpellier, France

\section{Keywords}

calcineurin inhibitors - liver transplantation solid tumours

Abbreviations
CNI, calcineurin inhibitors; HCC,
hepatocellular carcinoma; LT, liver
transplantation; PTLD, post-transplant
lymphoproliferative disorders.
Correspondence
GP Pageaux, Service d'Hépato-
Gastroentérologie et Transplantation, Hôpital
Saint-Eloi, 80 rue Augustin Fliche, 34295
Montpellier, France
Tel: +33 467337061
Fax: +33 499632247
e-mail: gp-pageaux@chu-montpellier.fr

\section{Abbreviations}

$\mathrm{CNI}$, calcineurin inhibitors; $\mathrm{HCC}$ hepatocellular carcinoma; LT, liver transplantation; PTLD, post-transplant

\section{Correspondence}

Saint-Eloi, 80 rue Augustin Fliche, 34295

Montpellier, France

Fax: +33499632247

e-mail: gp-pageaux@chu-montpellier.fr

\begin{abstract}
Background \& Aims: Increased rates of solid organ cancers post-liver transplantation have been reported, but the contribution of environmental factors and immunosuppressive therapy is not clear. This study's aims were to compare the incidence of de novo solid organ cancers after liver transplantation; identify risk factors independent of immunosuppressive therapy associated with these cancers; and assess the influence of calcineurin inhibitors on the appearance of these cancers. Methods: This single-centre study from 1991 to 2008 included 465 liver recipients who had survived for $\geq 1$ year. Gross incidence rates were standardized by age and sex, using the global population as a reference. In addition, 322 of the 465 patients treated for $\geq 1$ year with calcineurin inhibitors were studied. Results: Sixty-five (13.9\%) of the 465 patients developed de novo solid cancers. The overall relative risk was 3.7. Significantly increased relative risks were observed for digestive, oesophageal, colorectal, oral and lung cancers, but not for genito-urinary and breast cancers. Among the 65 patients who developed solid organ cancers, 43 died $(66.1 \%), 41$ from cancer. The two independent risk factors were pretransplant smoking $[P<0.0001$; odds ratio $=5.5(.5 ; 12)]$ and obesity $[P=0.0184$; odds ratio $=2.2(1.1 ; 4.3)]$. Of the 322 patients on calcineurin inhibitors, 55 (17\%) developed de novo solid cancers. Tacrolimus exposure level was a risk factor for de novo solid cancers $[P<0.0001$; OR $=15.3$ $(4.5 ; 52.2)]$. Conclusions: We recommend a change in immunosuppressive protocols with lifestyle/dietary guidelines and smoking cessation.
\end{abstract}

Liver transplantation (LT) has been the treatment of choice for end-stage liver disease since 1983 (1). More than $5500 \mathrm{LT} / y e a r$ are currently performed in Europe (2). Long-term survival has improved alongside surgery and immunosuppressive management, with 5- and 10year survival rates of $71 \%$ and $61 \%$ respectively. While infections and surgical complications are prominent causes of mortality in the early post-transplantation period, cancer is a major cause of late death (2-5).

Observational studies have shown a two- to three-fold increase in solid organ cancer rate and a 10-30-fold or higher increase in post-transplant lymphoproliferative disorders (PTLD) or skin cancer rates in LT patients compared to the general population (6-9). The chronic adverse effects of immunosuppressive drugs, pretransplant disorders and lifestyle are contributory.

Smoking and alcohol consumption are well-known, general risk factors for cancer development $(10,11)$. Calcineurin inhibitors (CNI), tacrolimus and cyclospor- ine, principle components of all immunosuppressive regimens used post-LT, are risk factors for the development of PTLD (12) or cutaneous cancers (13). The duration and intensity of immunosuppression are likely linked to the increased incidence of these solid organ cancers. There is a relationship between indication for LT and risk of cancer. Transplant recipients because of alcoholic liver disease (ALD) have a high risk for head and neck and oesophageal cancers, and those who receive transplants for primary sclerosing cholangitis associated with ulcerative colitis have a high risk for colorectal cancer (14).

The objectives of this study were to (i) compare the incidence of de novo solid organ cancers after LT in a single institution with regional data; (ii) identify risk factors independent of immunosuppressive therapy associated with de novo solid organ cancers post-LT and (iii) assess the influence of immunosuppressive treatment with CNI on de novo solid organ cancer appearance post-LT. 
Key Points

- The relative risk of de novo solid organ cancers is increased after liver transplantation.

- Prognosis is then poor.

- Risk factors include pretransplant smoking and obesity.

- Changes in immunosuppressive protocols, lifestyle, diet and smoking are recommended.

\section{Materials and methods}

\section{Comparison of incidences}

\section{Study population}

A prospective database was established in our centre in January 1991. The study population was adult recipients surviving $>6$ months after transplantation. Primary liver grafts were performed from January 1, 1991 to December 31, 2008. Multiorgan recipients were excluded. All patients began CNI treatment within 15 days after LT. Patients did not have extrahepatic malignancy signs preLT. Patients who developed hepatocellular carcinoma (HCC) recurrence, PTLD or skin cancer post-LT were excluded from the final analysis.

\section{Data collection}

Pretransplant characteristics and post-transplant followup were based on medical records and computerized information.

Pretransplant characteristics. Primary LT indication was based on the patient's history of alcohol consumption, and clinical, laboratory and histological findings, determined by transplant surgeons, hepatologists and the psychiatric team. HCC was considered the primary indication for LT in cases of compensated underlying cirrhosis, e.g. Child-Pugh A or Meld score <12. Primary indications were divided into four categories: ALD, post-hepatitis B or C cirrhosis, HCC and others. Liver disease severity at listing was characterized by the Child-Pugh classification and the MELD score. Smoking history, alcohol consumption, diabetes mellitus and body mass index (BMI) were recorded.

Prior to being short-listed for transplantation, all patients underwent a complete medical evaluation, including oral and nasal cavity examination and tumour scans in the brain, spinal cord, chest, abdomen and pelvis.

Immunosuppressive regimen. Patients' immunosuppressive therapies were recorded for cyclosporine, tacrolimus, azathioprine, mycophenolate mofetil, mycophenolic acid, everolimus and/or sirolimus. From 1991 to 1995 , the immunosuppressive regimen consisted of cyclosporine associated with azathioprine and corticosteroids. From
1995 to 2003, azathioprine was discontinued, and tacrolimus gradually replaced cyclosporine. Since 2003, mycophenolate mofetil has been added to tacrolimus or cyclosporine combined with corticosteroids. Cyclosporine and tacrolimus blood trough levels were maintained between $100-300 \mathrm{mg} / \mathrm{ml}$ and 5-15 $\mathrm{mg} / \mathrm{ml}$ respectively.

Post-transplant characteristics. During the first month, patients were seen twice/week with clinic appointments, then once/month in year one, every 2 months in year two, every 3 months in year three and then every 6 months, with additional visits if necessary. At each visit, information regarding diabetes, BMI, smoking history, alcohol consumption and cancer occurrence was collected prospectively. Diagnosis was based on histological analysis of a tumour biopsy or a surgical specimen. Patients who presented with cancers other than de novo solid cancer post-LT were excluded from the final analysis. The localization, histology, time between LT and diagnosis, and evolution of each cancer was recorded. Solid tumours were classified based on location.

Regional registry. Data on the general population came from the Hérault departmental cancer registry, established in 1983, which contains all new cancer cases in Hérault. The registry has the approval of the CNIL for personal data. Data recorded during 1991-2010 were used; sex and age distributions were available. The annual incidence of each cancer between 1991 and 2010 was calculated.

\section{Influence of immunosuppressive therapy}

\section{Study population}

Within the initial population, we selected patients for whom immunosuppressive therapy data were available. These patients survived $\geq 1$ year after LT and who received a single $\mathrm{CNI}$, tacrolimus or cyclosporine, for $\geq 1$ year from the transplant date. For CNI exposure, specific details of drug treatment were taken into account first by calculating TC means at all first-year endpoints. Total doses were then calculated using a Trapezoidal method for the first year post-LT.

\section{Statistical analysis}

The main characteristics of the population were described using frequencies and percentages (diabetes, alcohol consumption, tobacco consumption), means (age, Meld score, time from LT to cancer diagnosis) and standard deviation. Kaplan-Meier survival curves were estimated and compared by a log-rank test.

The main characteristics were compared according to solid cancer presence or absence using the Chi-square/ Fisher's test or Wilcoxon-Mann and Whitney tests if the variable was qualitative or quantitative. Bivariate analysis was performed to identify possible discriminating factors 
between cancer and no cancer, followed by multivariate stepwise logistic regression. Variables displaying a $P$ value $<0.15$ in the bivariate analysis were entered in the model (or 0.20 if the number of variables was $<4$ ); the optimal model was established using the Wald test.

The gross solid organ cancer incidence rate in postLT patients and the general population was standardized according to sex and age, taking the global population as a reference and compared using a statistical significance test $(P)$. The relative risk (RR) of developing de novo cancer in the LT population compared to the population from the registry could therefore be calculated with a confidence interval of $95 \%$ (95\% CI).

The SAS System version 9.2 for Windows, Copyright (c) 2002-2008 by SAS Institute Inc., Cary, NC, USA was used for all analyses.

\section{Results}

\section{Incidence comparison}

\section{Demographical data}

Among of 465 patients, there were 346 males (74.4\%) and 119 females $(25.6 \%)$, with a mean age at LT of $50.4 \pm 10.2$ years. The mean MELD score was $14.5 \pm 6.3$, with a majority of Child-Pugh B or C patients $(77.8 \%)$. The number of patients with primary indications for LT was as follows: ALD, $212(45.6 \%)$; post-hepatitis B or C cirrhosis, 104 (22.4\%); HCC, 64 (13.8\%); other causes, 85 (18.2\%) [cholestatic diseases, 25 (6 with primary sclerosing cholangitis); auto-immune cirrhosis, 9; metabolic diseases, 6; non-HCC tumours, 6; NASH, 6; haemochromatosis, 2; acute liver failure, 17; miscellaneous, 14]. Active smoking was reported in $60.3 \%$ and $39.7 \%$ of patients before and after LT respectively. Excessive alcohol consumption was reported in $70.1 \%$ and $14.1 \%$ of patients before and after LT respectively. Excess body weight was reported in $18.8 \%$ of patients. The median follow-up was 7.8 years.

\section{De novo solid organ cancer after LT}

One hundred and six patients developed at least one de novo malignancy after LT (cumulative frequency $22.8 \%$ ): 28 skin cancers, 13 PTLD and 65 solid organ cancers. For the latter, the mean time from LT to diagnosis was $6.3 \pm 4.3$ years (median 6 years). The three-, five- and 10 -year cumulative frequencies were $3.8 \%, 5.4 \%$ and $11.5 \%$ respectively. The most common solid cancers diagnosed were oral $(n=17,26.1 \%)$, pulmonary $(n=15,23 \%)$, digestive system $(n=15,23 \%)$ and other $(n=18,27.9 \%)$. Among digestive system cancers, there were eight colorectal, four oesophageal, two anal and one pancreatic cancer. Among other cancers, there were eight prostate and genito-urinary, four breast, three nonKaposi sarcomas and three metastases with unknown primary cancers. Eighteen patients developed a second solid organ cancer (six oral, seven pulmonary, two colorectal, one pancreatic, one prostate and one thyroid cancer). Two patients presented a third cancer (prostate).

\section{Relative risk compared with the general population}

The gross and standardized solid cancer incidences and RR of developing a solid cancer after LT are described in Table 1. The overall RR as compared to the general population was 3.7 (95\% confidence interval 2.8-4.9). Significantly increased RRs were observed for overall digestive (RR 4.6), oesophageal (RR 10.5), colorectal (RR 2.7), oral (RR 15.8) and lung cancers (RR 5.1), but not for genito-urinary and breast cancers.

\section{Survival}

Of 465 patients, the five- and 10-year overall survival was $85.2 \%$ and $69.1 \%$ respectively. One hundred and fifty-five patients died during follow-up from: malignancies, 48 (31\%), initial disease recurrence, 45 (29\%), cardiovascular disease, 17 (11\%), sepsis, $15(9.7 \%)$, chronic rejection, $4(2.6 \%)$, renal failure, $4(2.6 \%)$ and miscellaneous causes, 22 (14.1\%).

Among the 65 patients who developed solid organ cancer, 43 died (66.1\%), and 41 were cancer deaths. The overall survival of patients who developed solid organ cancers was significantly lower than for those without cancer $(P<0.0001$, Fig. 1$)$ : 10 -year overall survival was $50.7 \%$ vs. $73.5 \%$ for patients with or without cancer respectively $(P=0.002)$.

\section{Risk factors associated with post-LT de novo solid organ cancers}

Post-LT solid cancer development risk factors are described in Table 2. By multivariate analysis, the two independent risk factors were smoking before LT $[P<0.0001 ; \quad$ OR $=5.5 \quad(2.5 ; 12)] \quad$ and obesity $(P=0.0184 ; \mathrm{HR}=2.2(1.1 ; 4.3)]$.

The same analysis was performed in 38 patients who developed a type of cancer for which smoking is a known risk factor (Table S1). Smoking before and after LT were the only two independent risk factors for cancer by multivariate analysis.

In the other 27 patients, obesity was the only risk factor found for post-LT cancer (Table S1). There was no significant difference in the time for 'smoking-induced' and 'non-smoking-induced' cancers to occur post-LT (6.2 and 6.4 years respectively).

\section{Influence of immunosuppressive therapy}

\section{Tacrolimus exposure}

Two hundred and sixty-six patients were treated with tacrolimus; 247 patients started the drug within 15 days of LT, and continued for at least 1 year. In this group, $72.1 \%$ were male and the median age was 48.1 years. 
Table 1. Comparison of the solid cancer incidences post-LT and in the general population. Incidences expressed per 100,000 persons and per annum

\begin{tabular}{|c|c|c|c|c|c|c|}
\hline & Solid cancer & Oral cancer & Lung cancer & Digestive cancer & Colorectal cancer & Oesophageal cancer \\
\hline \multicolumn{7}{|l|}{ Hérault registry } \\
\hline Gross incidence & 339.8 & 26.9 & 49.0 & 70.1 & 59.1 & 6.7 \\
\hline 95\% Cl lower limit & 337.2 & 26.1 & 48.0 & 68.9 & 58.0 & 6.3 \\
\hline 95\% Cl upper limit & 342.5 & 27.6 & 50.0 & 71.3 & 60.2 & 7.1 \\
\hline Standardized incidence & 203.4 & 17.8 & 29.5 & 39.9 & 33.3 & 4.0 \\
\hline $95 \% \mathrm{Cl}$ lower limit & 199.4 & 17.7 & 29.3 & 39.6 & 33.1 & 4.0 \\
\hline 95\% Cl upper limit & 207.4 & 17.9 & 29.7 & 40.2 & 33.5 & 4.0 \\
\hline \multicolumn{7}{|l|}{ LT population } \\
\hline Gross incidence & 1310.8 & 352.9 & 302.5 & 327.7 & 176.5 & 100.8 \\
\hline 95\% Cl lower limit & 998.8 & 209.0 & 171.8 & 190.3 & 84.1 & 37.8 \\
\hline 95\% Cl upper limit & 1720.2 & 595.9 & 532.7 & 564.4 & 370.1 & 268.7 \\
\hline Standardized incidence & 760.0 & 281.4 & 150.5 & 145.3 & 88.8 & 41.8 \\
\hline 95\% Cl lower limit & 721.7 & 268.2 & 148.9 & 143.7 & 88.1 & 41.6 \\
\hline 95\% Cl upper limit & 800.3 & 295.3 & 152.1 & 147.0 & 89.6 & 42.1 \\
\hline Relative risk & 3.7 & 15.8 & 5.1 & 4.6 & 2.7 & 10.5 \\
\hline 95\% Cl lower limit & 2.8 & 9.4 & 2.9 & 2.6 & 1.3 & 3.9 \\
\hline $95 \%$ Cl upper limit & 4.9 & 26.7 & 9.0 & 7.8 & 5.6 & 27.9 \\
\hline$P$ value & $<0.001$ & $<0.001$ & $<0.001$ & $<0.001$ & 0.007 & $<0.001$ \\
\hline
\end{tabular}

$95 \% \mathrm{Cl}=95 \%$ confidence interval

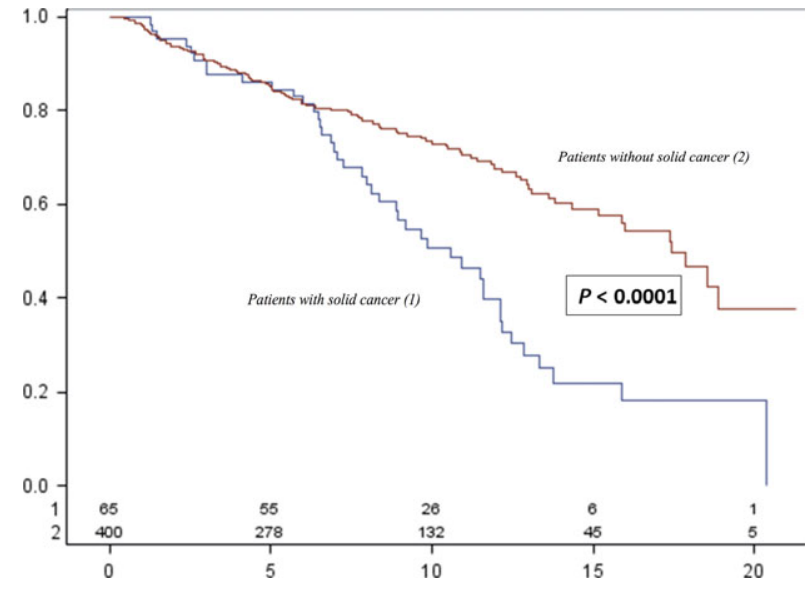

Fig. 1. Overall survival after liver transplantation. The overall survival of patients who developed solid organ cancer was significantly lower than for those without cancer $(P<0.0001)$

The mean follow-up was $8 \pm 3.5$ years. Forty-three patients developed de novo solid organ cancers after LT including 10 head and neck, 10 digestive, 11 lung and 12 solid cancers at other sites. The mean time from LT to diagnosis was $6 \pm 3.4$ years. Risk factors are shown in Table 3. A mean annual tacrolimus blood trough concentration $>8 \mathrm{ng} / \mathrm{ml}$ during the first year post-LT was an independent risk factor for these cancers by multivariate analysis $[P<0.001 ; \mathrm{OR}=15.3$; 95\% CI (4.5-52.2)].

\section{Cyclosporine exposure}

Eighty-six patients were on cyclosporine; 75 patients started cyclosporine at least 15 days after LT, and continued for at least 1 year $(73.3 \%$ of males, median age 48.2 years). The mean follow-up was $12.3 \pm$ 5.6 years. Twelve patients developed de novo solid organ cancers after LT: four head and neck, three digestive, two lung and three other cancers. The mean time from LT to diagnosis was $8.8 \pm 5.3$ years. Risk factors for solid organ cancer are shown in Table 4. Through univariate analysis, a mean annual cyclosporine blood trough concentration $>215 \mathrm{ng} / \mathrm{ml}$ during the first year post-LT trended towards significance $(P=0.06)$, but the only independent risk factor for cancer by multivariate analysis was post-LT smoking $[P=0.002 ; \mathrm{OR}=29$; IC95\%(3.36-251)].

\section{Discussion}

Several studies have reported incidences of de novo malignancies (PTLD, skin cancer, solid organ cancer) after LT ranging from $3 \%$ to $26 \%$, depending mainly on follow-up length, with a continuous increase to $19 \%$ and $34 \%$ at 10 and 15 years respectively (69,15). Observational studies have shown a two- to three-fold elevated risk of solid organ cancers, with a higher mortality rate compared to the general population $(7,10,15)$. In our series of $465 \mathrm{LT}$ recipients who survived more than 6 months after LT, the prevalence of de novo solid organ cancers was $14 \%$, with a significantly poorer 10 -year survival. The overall RR compared with the general population was 3.7. Therefore, our results are consistent with those previously reported for post-LT de novo malignancies. Because skin cancer has no impact on survival and PTLD are more rarely seen, we chose to focus on solid cancers. 
Table 2. Risk factors for developing de novo solid cancer post-LT, univariate and multivariate analyses

\begin{tabular}{|c|c|c|c|c|c|}
\hline \multicolumn{6}{|c|}{ Univariate analysis of solid cancer risk factors $(n=465)$} \\
\hline Variable & $\begin{array}{l}\text { No solid cancer }(N=400) \\
\mathrm{n} / \mathrm{N}(\%)\end{array}$ & $\begin{array}{l}\text { Solid cancer }(N=65) \\
\mathrm{n} / \mathrm{N}(\%)\end{array}$ & $P$ value & OR & $95 \% \mathrm{Cl}$ \\
\hline Age at $L T>50$ years & $222 / 400(55.5)$ & $40 / 65(61.5)$ & 0.36 & & \\
\hline Male & $296 / 400(74)$ & $50 / 65(76.9)$ & 0.62 & & \\
\hline Excessive $\mathrm{OH}$ before $\mathrm{LT}$ & $241 / 371(65)$ & $53 / 63(84.1)$ & 0.003 & 2.9 & $(1.4 ; 5.8)$ \\
\hline Excessive $\mathrm{OH}$ after $\mathrm{LT}$ & $44 / 383(11.5)$ & $12 / 64(18.8)$ & 0.10 & & \\
\hline Diabetes & $142 / 391(36.3)$ & $26 / 64(40.6)$ & 0.51 & & \\
\hline Smoking before LT & $200 / 372(53.8)$ & $54 / 64(84.4) 1$ & $<0.0001$ & 4.6 & $(2.3 ; 9.4)$ \\
\hline Smoking after LT & $119 / 370(37.2)$ & $36 / 64(56.3)$ & 0.0002 & 2.7 & $(1.6 ; 4.6)$ \\
\hline Obesity & $60 / 381(15.8)$ & $17 / 62(27.4)$ & 0.02 & 2 & $(1.1 ; 3.8)$ \\
\hline $\begin{array}{l}\text { Patients included in the } \\
\text { Variable }\end{array}$ & $\begin{array}{r}J=465): \text { multivariate analysi } \\
P \text { value }\end{array}$ & id cancer risk factors & OR & & Wald $95 \% \mathrm{Cl}$ \\
\hline Smoking before LT & $<0.0001$ & & 5.5 & & $(2.5 ; 12)$ \\
\hline Obesity & 0.0184 & & 2.2 & & $(1.1 ; 4.3)$ \\
\hline
\end{tabular}

OR, odds ratio; $\mathrm{Cl}$, confidence interval.

Table 3. Univariate and multivariate analysis of risks factors for de novo solid cancers post-LT with tacrolimus

\begin{tabular}{|c|c|c|c|c|c|c|}
\hline \multirow[b]{3}{*}{ Variable } & \multicolumn{6}{|c|}{ Tacrolimus 1 year (43 with C \& 204 without C) } \\
\hline & \multicolumn{3}{|c|}{ Univariate analysis } & \multicolumn{3}{|c|}{ Multivariate analysis } \\
\hline & $P$ value & OR & $95 \% \mathrm{Cl}$ & $P$ value & OR & $95 \% \mathrm{Cl}$ \\
\hline Age $>50$ & 0.37 & NS & & & & \\
\hline Male & 0.7 & NS & & & & \\
\hline Alcohol pre-LT & 0.07 & NS & & & & \\
\hline Alcohol post-LT & 0.27 & NS & & & & \\
\hline Diabetes mellitus & 0.56 & NS & & & & \\
\hline Tobacco pre-LT & 0.0001 & 5.1 & $(2.1-12.6)$ & 0.002 & 4.54 & $(1.74-11.8)$ \\
\hline Tobacco post-LT & 0.002 & 2.8 & $(1.4-5.5)$ & & & \\
\hline Obesity & 0.12 & NS & & & & \\
\hline $\mathrm{CNI}$ level exposure* & $<0.0001$ & 11.2 & $(3.9-32.5)$ & $<0.0001$ & 15.3 & $(4.5-52.2)$ \\
\hline
\end{tabular}

* Mean annual tacrolimus blood trough concentration $>8 \mathrm{ng} / \mathrm{ml}$ during the first year after LT and $>7 \mathrm{ng} / \mathrm{ml}$ during the 3 years after LT.

LT, liver transplantation; NS, non-significant; C, cancer. CNI, calcineurin inhibitors.

Table 4. Univariate and multivariate analysis of risks factors for de novo solid cancers after LT in with cyclosporine

\begin{tabular}{|c|c|c|c|c|c|c|}
\hline \multicolumn{7}{|c|}{ Risks factors for de novo solid cancer after LT with cyclosporine } \\
\hline & \multicolumn{6}{|c|}{ Cyclosporine 1 year (12 with C \& 63 without C) } \\
\hline & \multicolumn{3}{|c|}{ Univariate analysis } & \multicolumn{3}{|c|}{ Multivariate analysis } \\
\hline Variable & $P$ value & OR & $95 \% \mathrm{Cl}$ & $P$ value & OR & $95 \% \mathrm{Cl}$ \\
\hline Age $>50$ & 0.78 & NS & & & & \\
\hline Male & 1 & NS & & & & \\
\hline Alcohol pre-LT & 0.06 & NS & & & & \\
\hline Alcohol post-LT & 0.17 & NS & & & & \\
\hline Diabetes mellitus & 1 & NS & & & & \\
\hline Tobacco pre-LT & 0.004 & 12.7 & $(1.5-105)$ & & & \\
\hline Tobacco post-LT & $<0.0001$ & 14.5 & $(2.8-75)$ & 0.002 & 29 & $(3.36-251)$ \\
\hline Obesity & 0.21 & NS & & & & \\
\hline CNI level exposure* & 0.06 & NS & & NS & NS & NS \\
\hline
\end{tabular}

*Mean annual cyclosporine blood trough concentration $>215 \mathrm{ng} / \mathrm{ml}$ during the first year after LT and > $175 \mathrm{ng} / \mathrm{ml}$ during the 3 years after LT.

LT, liver transplantation; NS, non-significant; C, cancer. CNI, calcineurin inhibitors. 
The incidence of many cancers peaks within 2 years of LT (6). For most solid cancers it subsequently declines steadily, but increases again 5 years post-transplantation, probably reflective of aggressive immunosuppression during the early post-transplant period and the long-term use of carcinogens. In French LT centres, the most frequently used immunosuppressive treatment comprises of CNI (usually tacrolimus), mycophenolate mofetil and steroids for the first 3 months, and sometimes induction with CD25 antibodies. The target tacrolimus blood concentration is $8-12 \mathrm{ng} / \mathrm{ml}$. Evidence from animal studies suggesting that CNIs have carcinogenic potential, possibly because of Ras pathway activation (16), induction of tumour growth and metastatic potential through TGF- $\beta 1$ activation $(17,18)$, and disruption of angiogenesis and apoptosis (19-21), but this has yet to be confirmed clinically. In kidney transplant recipients, the incidence of cancers (mainly skin malignancies) was higher in patients with elevated cyclosporine target levels (22). We identified a dose-dependent effect of tacrolimus, but not cyclosporine, therefore we have now associated the degree of CNI exposure with post-LT solid organ cancer risk. Notably, our data suggest a dose-response relationship between early exposure levels to tacrolimus and post-LT solid cancer risk. The absence of similar results with cyclosporine is probably because of the sample size $(n=75)$.

The major cause of de novo solid organ cancers in the post-LT period is related to immunosurveillance loss induced by immunosuppressive agents coinciding with other carcinogenesis-associated risk factors, including inflammatory bowel disease, smoking and alcohol abuse.

Our cohort had a high proportion of patients who received transplants for ALD, but also for another primary indication (viral disease, HCC) with a history of excessive alcohol consumption. ALD as an indication for LT is associated with an increased risk of de novo malignancies, especially oesophageal and oral cancers $(5,23)$. This suggests that besides chronic immunosuppression, oncogenic factors may also include alcohol metabolites, cigarette smoking products and intrinsic carcinogenic properties of CNI (16-19), but must be confirmed clinically. The precise oncogenic factors in LT and ALD patients are unclear. Patients with ALD frequently have a history of pre-LT smoking and often promptly resume after LT, increasing the de novo solid organ cancer risk (24). This explains the high prevalence of oral, lung and oesophageal cancers in our population. We also observed a significantly increased RR for colorectal cancer. This is well established in patients with primary sclerosing cholangitis with associated ulcerative colitis. Only six of our patients had LT because of primary sclerosing cholangitis. In a systematic review and meta-analysis, the non-primary sclerosing cholangitis RR for colorectal cancer was 1.8 (25). There are no conclusive recommendations for colorectal screening in non-primary sclerosing cholangitis LT recipients.
Importantly, excessive alcohol consumption is related to a significantly increased risk of colorectal adenoma and cancer (26).

The development of de novo solid organ cancers majorly impacts the outcome of LT recipients because of poor prognosis, as the outcome is generally worse compared to the general population with the same malignant diseases. One recent study showed a median survival of $<3$ years after the cancer diagnosis (10). In our population, cancer was the leading long-term cause of death, and $63 \%$ of patients with solid cancer died from it. While the reasons are not clear, it is thought that immunosuppression leads to increased proliferation and spread, explaining why these cancers are often discovered at an advanced stage thereby decreasing the treatment options. Most likely, we must change our immunosuppressive strategies to rapidly decrease CNI concentrations. Inhibitors of proliferation signals, such as m-TOR, could be used to avoid an increased rejection rate. These drugs also have preclinically demonstrated anti-oncogenic effects and are currently being investigated in clinical trials (27).

Substantial literature supports increased morbidity and mortality among post-LT smokers. In most cases, post-LT smoking returns after a brief cessation because of surgery and hospitalization. Data concerning post-LT smoking should therefore be analysed and interpreted in consideration of pre-LT tobacco use and dependence. Smoking and immunosuppression may have adverse additive effects, especially for developing malignancies. The majority of patients who smoke before LT will relapse post-LT, and tobacco use could exacerbate or even outweigh alcohol use for impact on morbidity (24). Jimenez et al. reported a $2.1 \%$ incidence of lung cancer in 701 LT recipients (28), and 13/15 lung cancer patients were smokers. Similar results have been reported for oral and oesophageal squamous cell carcinoma, where the cumulative rate of malignancies at 10 years was $12.7 \%$ in active smokers vs. $2.1 \%$ in nonsmokers (29). Therefore, tobacco addiction should be identified and treated during the pretransplant period. Recently, it was shown that LT recipients who quit smoking had a lower incidence of smoking-related malignancies compared to those who continued, suggesting that cessation may protect against de novo cancers (11).

Obesity and excess body weight are independent risk factors for breast, endometrial, oesophageal and colon cancers (30). Moreover, increased body weight is associated with increased death rates for all cancers (31). The pathophysiological relationship between BMI and cancer risk remains hypothetical. Animal data suggest that obesity-associated hormonal abnormalities may be involved, including: hyperinsulinaemia, elevated insulin-like growth factor and its bioavailability, decreased adiponectin, and increased estradiol, disturbances likely to be mutagenic and anti-apoptotic (30). The obesityassociated inflammatory state is another carcinogenic 
factor. Liver transplant recipients often present with metabolic syndrome (32), putting them at risk for solid cancers. Regular physical activity and a balanced diet are essential in these patients for prevention.

In conclusion, we have demonstrated a significantly increased risk of solid cancer in LT recipients compared with the general population, with poor prognosis. Solid cancer risk factors include smoking and obesity, amplified by early CNI exposure. Immunosuppressive protocol changes combined with lifestyle and dietary guidelines and smoking cessation are theoretically the best preventive measures.

\section{Acknowledgements}

All authors contributed to the conception, design, data collection and writing of this article.

Conflict of interest: Georges-Philippe Pageaux is a member of Advisory boards, Astellas, Novartis. Christophe Carenco, Stéphanie Faure, Astrid Herrero, Eric Assenat, Yohan Duny, Guillaume Danan, Michaël Bismuth, Gérald Chanques, José Ursic-Bedoya, Samir Jaber, Dominique Larrey and Francis Navarro have no conflicts of interest.

\section{References}

1. National Institutes of Health Consensus Development Conference Statement. liver transplantation - June 20-23, 1983. Hepatology 1984; 4: 107S-10S.

2. Adam R, Karam V, Delvart V, et al. Evolution of indications and results of liver transplantation in Europe. A report from the European liver transplant registry (ELTR). J Hepatol 2012; 57: 675-88.

3. Gelson W, Hoare M, Dawwas MF, et al. The pattern of late mortality in liver transplant recipients in the United Kingdom. Transplantation 2011; 91: 1240-4.

4. Haagsma EB, Hagens VE, Schaapveld M, et al. Increased cancer risk after liver transplantation: a population-based study. J Hepatol 2001; 34: 84-91.

5. Watt KD, Pedersen RA, Kremers WK, Heimbach JK, Charlton MR. Evolution of causes and risk factors for mortality post-liver transplant: results of the NIDDK long-term follow-up study. Am J Transplant 2010; 10: 1420-7.

6. Aberg F, Pukkala E, Höckerstedt K, Sankila R, Isoniemi H. Risk of malignant neoplasms after liver transplantation: a population-based study. Liver Transpl 2008; 14: 1428-36.

7. Engels EA, Pfeiffer RM, Fraumeni JF Jr, et al. Spectrum of cancer risk among US solid organ transplant recipients. JAMA 2011; 306: 1891-901.

8. Baccarani U, Piselli P, Serraino D, et al. Comparison of de novo tumours after liver transplantation with incidence rates from Italian cancer registries. Dig Liver Dis 2010; 42: 55-60.

9. Collett D, Mumford L, Banner NR, Neuberger J, Watson C. Comparison of the incidence of malignancy in recipients of different types of organ: a UK registry audit. Am J Transplant 2010; 10: 1889-96.

10. Watt KD, Pedersen RA, Kremers WK, et al. Long-term probability of and mortality from de novo malignancy after liver transplantation. Gastroenterology 2009; 137: 2010-7.

11. Herrero JI, Pardo F, D'Avola D, et al. Risk factors of lung, head and neck, esophageal and kidney and urinary tract carcinomas after liver transplantation: the effect of smoking withdrawal. Liver Transpl 2011; 17: 402-8.

12. Bakker NA, van Imhoff GW, Verschuuren EA, van Son WJ. Presentation and early detection of post-transplant lymphoproliferative disorder after solid organ transplantation. Transpl Int 2007; 20: 207-18.

13. Mithoefer AB, Supran S, Freeman RB. Risk factors associated with the development of skin cancer after liver transplantation. Liver Transpl 2002; 8: 939-44.

14. Herrero JI. De novo malignancies following liver transplantation: impact and recommendations. Liver Transpl 2009; 15: S90-4.

15. Finkenstedt A, Graziadei IV, Oberaigner W, et al. Extensive surveillance promotes early diagnosis and improved survival of de novo malignancies in liver transplant recipients. Am J of Transplant 2009; 9: 2355-61.

16. Datta D, Contreras AG, Basu A, et al. Calcineurin inhibitors activate the proto-oncogene Ras and promote protumorigenic signals in renal cancer cells. Cancer Res 2009; 69: 8902-9.

17. Hojo M, Morimoto T, Maluccio M, et al. Cyclosporine induces cancer progression by a cell-autonomous mechanism. Nature 1999; 397: 530-4.

18. Maluccio M, Sharma V, Lagman M, et al. Tacrolimus enhances transforming growth factor-betal expression and promotes tumor progression. Transplantation 2003; 76: 597-602.

19. Yarosh DB, Pena AV, Nay SL, Canning MT, Brown DA. Calcineurin inhibitors decrease DNA repair and apoptosis in human keratinocytes following ultraviolet B irradiation. J Invest Dermatol 2005; 125: 1020-5.

20. Guba M, von Breitenbuch P, Steinbauer M, et al. Rapamycin inhibits primary and metastatic tumor growth by antiangiogenesis: involvement of vascular endothelial growth factor. Nat Med 2002; 8: 128-35.

21. Koehl GE, Andrassy J, Guba M, et al. Rapamycin protects allografts from rejection while simultaneously attacking tumors in immunosuppressed mice. Transplantation 2004; 77: 1319-26.

22. Dantal J, Hourmant M, Cantarovich D, et al. Effect of long-term immunosuppression in kidney-graft recipients on cancer incidence: randomized comparison of two cyclosporine regimens. Lancet 1998; 351: 623-8.

23. Schrem H, Kurok M, Kaltenborn A, et al. Incidence and long-term risk of de novo malignancies after liver transplantation with implications for prevention and detection. Liver Transplant 2013; 19: 1252-61.

24. DiMartini A, Javed L, Russell S, et al. Tobacco use following liver transplantation for alcoholic liver disease: an underestimated problem. Liver Transpl 2005; 11: 679-83.

25. Sint Nicolaas J, de Jonge V, Steyerberg EW, et al. Risk of colorectal carcinoma in post-liver transplant patients : a systematic review and meta-analysis. Am J of Transplant 2010; 10: 869-76.

26. Zhu JZ, Wang YM, Zhou QY, et al. Systematic review with meta-analysis : alcohol consumption and the risk of colorectal adenoma. Aliment Pharmacol Ther 2014; 40: 325-37.

27. Campistol JM, Cuervas-Mons V, Manito N, et al. New concepts and best practices for management of pre- and 
post-transplantation cancer. Transplant Rev (Orlando) 2012; 26: 261-79.

28. Jimenez C, Manrique A, Marquès E, et al. Incidence and risk factors for the development of lung tumors after liver transplantation. Transpl Int 2007; 20: 57-63.

29. Van der Heide F, Dijkstra G, Porte RJ, et al. Smoking behavior in liver transplant recipients. Liver Transpl 2009; 15: 648-55.

30. Schlienger JL, Luca F, Vinzio S, et al. Obesity and cancer. Rev Med Interne 2009; 30: 776-82.

31. Calle EE, Rodriguez C, Walker-Thurmond K. Overweight, obesity and mortality from cancer in a prospectively studied cohort of US adults. N Engl J Med 2003; 348: 1625-38.
32. Watt KD. Metabolic syndrome: is immunosuppression to blame? Liver Transpl 2011;17(Suppl. 3): S36-42. 